\title{
Relevância do Comitê de Ética em Pesquisa nas publicações científicas
}

\author{
Cristina Muccioli, Paulo E.C. Dantas, Mauro Campos, Harley E.A. Bicas
}

Da efervescência das idéias e hipóteses científicas à execução de estudos para desvendar suas respostas, interpõem-se rígidas normas ético-científicas, criadas para proteger tanto o indivíduo da pesquisa (seja ele humano ou não), quanto à credibilidade de seus resultados e, por conseqüência, do pesquisador.

No Brasil, desde outubro de 1996, foram estabelecidas as chamadas Diretrizes e Normas de Pesquisa Envolvendo Seres Humanos, por meio da Resolução 196/96 do Conselho Nacional de Saúde e suas complementares, com o objetivo principal de garantir o respeito à pessoa. Garantia que se estende não só ao sujeito da pesquisa, ao pesquisador e à equipe de pesquisa, mas também à sociedade como um todo.

A avaliação ética de um projeto de pesquisa em saúde baseia-se na qualificação do projeto de pesquisa, na experiência da equipe de pesquisadores envolvidos, na avaliação do risco-benefício envolvido, na informação precisa e detalhada ao sujeito da pesquisa e conseqüente obtenção do seu consentimento informado e na prévia avaliação de possíveis efeitos da investigação pretendida, realizada por um comitê de ética qualificado.

A Pesquisa Clínica é o estudo sistemático que segue métodos científicos aplicáveis aos seres humanos, denominados voluntários, ou "sujeitos de pesquisa". Quando realizada com medicamentos tem o objetivo de verificar efeitos, analisar absorção, distribuição, metabolismo e excreção, com finalidade de estabelecer eficácia e segurança do produto.

É importante ressaltar que, para todo e qualquer tipo de pesquisa a ser realizada, deverá ser feito obrigatoriamente o encaminhamento do protocolo de pesquisa para o comitê de ética da Instituição e, apenas após aprovação do protocolo, é que o estudo poderá ser realizado. Isto é válido não só para pesquisas com seres humanos, mas também para pesquisa experimental, revisão de prontuários, análise retrospectiva, análise anátomo-patológica, levantamento genético, levantamento social, levantamento epidemiológico e pesquisas envolvendo somente questionários, dentre outras.

O Comitê de Ética em Pesquisa (CEP) é um colegiado interdisciplinar e independente, com munus público, que deve existir nas instituições que realizam pesquisas envolvendo seres humanos no Brasil. Ele foi criado com a finalidade de defender os interesses dos sujeitos da pesquisa em sua integridade e dignidade e contribuir para o desenvolvimento da pesquisa dentro dos padrões éticos (Normas e Diretrizes Regulamentadoras da Pesquisa Envolvendo Seres Humanos Resolução CNS 196/96, II.4).
O CEP é responsável pela avaliação e acompanhamento dos aspectos éticos de todas as pesquisas envolvendo seres humanos. Este papel está bem estabelecido nas diversas diretrizes éticas internacionais (Declaração de Helsinque, Diretrizes Internacionais para as Pesquisas Biomédicas envolvendo Seres $\mathrm{Hu}$ manos - CIOMS) e brasileiras (Resolução CNS 196/96 e complementares), que ressaltam a necessidade de revisão ética e científica de pesquisa envolvendo seres humanos, visando salvaguardar a dignidade, os direitos, a segurança e o bem-estar do sujeito de pesquisa. Além disso, o CEP contribui para a qualidade das pesquisas e para a discussão do papel da pesquisa no desenvolvimento institucional e social da comunidade.

Muito importante também é a contribuição do CEP exercendo papel consultivo e, em especial, papel educativo para assegurar a formação continuada dos pesquisadores da instituição e promover a discussão dos aspectos éticos das pesquisas em seres humanos na comunidade.

Portanto, de acordo com a Resolução CNS 196/96, "toda pesquisa envolvendo seres humanos deverá ser submetida à apreciação de um CEP". O CEP irá então analisar os projetos recebidos, sobre os quais deverá emitir parecer em período máximo de 30 dias. Após análise do protocolo pelo CEP, este deverá obedecer ao fluxograma para pesquisas envolvendo seres humanos.

Quando a pesquisa clínica for realizada em instituição que não possua um CEP, deverá ser encaminhada uma solicitação à CONEP para que esta indique um CEP que possa fazer a avaliação do projeto.

A CONEP é uma comissão assessora do Conselho Nacional de Saúde, criada pela Resolução 196/96, com a função de implementar as normas e diretrizes regulamentadoras de pesquisa envolvendo seres humanos. Tem função consultiva, deliberativa, normativa e educativa, atuando conjuntamente com uma rede de CEPs, organizados em diferentes instituições e outras instâncias.

Esse fluxograma de encaminhamento da pesquisa científica deverá ser seguido e respeitado rigorosamente toda vez que se pretenda fazer pesquisa. Esta é uma forma de garantir que todo o processo seja realizado de acordo com as regulamentações universais de ética em pesquisa.

Da mesma forma, acredita-se que todo trabalho enviado para publicação tenha sido previamente submetido a essas mesmas regras éticas. Os editores das diversas revistas científicas indexadas em bases de dados nacionais e internacionais e que contam com "peer review", geralmente incluem nas suas 
normas de publicação a necessidade do trabalho enviado para a publicação ter sido submetido à aprovação de um comitê de ética em pesquisa. Algumas revistas indexadas no "Medline" e que estão entre as "Top 10" na classificação das melhores publicações científicas, exigem o encaminhamento de carta de aprovação do CEP Institucional para os artigos científicos enviados e submetidos à análise dos revisores, além de carta com assinatura do Termo de Consentimento Livre e Esclarecido dos pacientes no caso de relato de caso clínico.
Os Arquivos Brasileiros de Oftalmologia, dentro de sua política de qualificação da produção científica no Brasil e America Latina, é signatário da política de exigência da comprovação da aprovação de todo e qualquer estudo científico submetido para análise de publicação. Dessa forma, acreditamos que, além de incentivarmos o cumprimento das regulamentações oficiais oriundas das CONEPs e CEPs, elevamos a um patamar ético considerável toda a produção científica por nós publicada. 